\title{
Coping Strategy and Depression among Caregivers of Cancer Patients Receiving Palliative Care
}

\author{
Noor Melissa Nor Hadi1, 2, Fazlina Ahmad³, Mohamad Rodi Isa4, \\ Salmi Razali1,5 \\ 1Department of Psychiatry, ${ }^{4}$ Department of Public Health and Preventive Medicine, \\ ${ }^{5}$ Maternofetal and Embryo Research Group (MatE), Faculty of Medicine, \\ Universiti Teknologi MARA, Malaysia \\ 2Department of Psychiatry and Mental Health, Hospital Tuanku Fauziah, Perlis, Malaysia \\ ${ }_{3}^{3}$ Palliative Care Unit, Department of Medicine, Hospital Sultanah Bahiyah, Kedah, Malaysia
}

noormelissanh@gmail.com, fazlina77@yahoo.com, rodi@uitm.edu.my, drsalmi@uitm.edu.my

Tel.: +603-61265000

\begin{abstract}
Major depressive disorder (MDD) put caregivers of palliative cancer patients (CPCP) and the patients at risk for various physical and psychological complications. This study aimed to determine the prevalence of MDD and its contributing factors among CPCP. The diagnosis of MDD was determined using the Mini International Neuropsychiatric Inventory. Pro forma and validated questionnaires were used to assess sociodemography, caregiving and patient factors, coping strategy, and social support. About $6 \%$ of CPCP had MDD. Predictors for MDD were coping by behavioural disengagement and positive reframing. These coping strategies are crucial for CPCP to have optimum mental health status.
\end{abstract}

Keywords: Caregiver, Cancer, Palliative, Depression, Coping Strategy

eISSN: 2398-42870 2020. The Authors. Published for AMER ABRA cE-Bs by e-International Publishing House, Ltd., UK. This is an open access article under the CC BYNC-ND license (http://creativecommons.org/licenses/by-nc-nd/4.0/). Peer-review under responsibility of AMER (Association of Malaysian Environment-Behaviour Researchers), ABRA (Association of Behavioural Researchers on Asians) and cE-Bs (Centre for Environment-Behaviour Studies), Faculty of Architecture, Planning \& Surveying, Universiti Teknologi MARA, Malaysia. DOI: https://doi.org/10.21834/ebpj.v5i14.2334

\subsection{Introduction}

Cancer is a leading cause of death worldwide, accounting for an estimated 9.6 million deaths in 2018 (World Health Organization, 2018). In Malaysia, cancer is the fourth leading cause of death which contributes to $12.6 \%$ of all deaths in government hospitals and $26.7 \%$ in private hospitals (Ministry of Health, 2018).

In Asian cultures, family, the caregivers of palliative cancer patients (CPCP) assume caregiving roles out of obligation and filial piety. As cancer progresses and death grow closer, the needs of patients with cancer and their CPCP intensify. Patients' dependency limit caregiver's freedom and mobilisation, increase the feeling of exhaustion and fatigue and at the same time, reduce patients' functioning and responsibility of caregiving (Mahadevan et al., 2013). As a result, many CPCP are more prone to emotional and psychological difficulties, such as depression and anxiety (Rumpold et al., 2016). In a recent systematic review and meta-analysis, depression in cancer CPCP was $42.3 \%$ (Wen et al., 2019).

Among the CPCP, depression has been associated with specific CPCP demographic factors such as younger age, female gender and spousal relationship, inadequate support received by CPCP and negative appraisals of caregiving demand (Teixeira et al., 2018). Caregiver burden level also was found to be a predictor of depression and anxiety (Wen et al., 2019). Often CPCP suffers from the burden of caring the patients at home, due to spending their time mostly around the patients and often neglecting their own self-care

eISSN: 2398-4287C 2020. The Authors. Published for AMER ABRA cE-Bs by e-International Publishing House, Ltd., UK. This is an open access article under the CC BYNC-ND license (http://creativecommons.org/licenses/by-nc-nd/4.0/). Peer-review under responsibility of AMER (Association of Malaysian Environment-Behaviour Researchers), ABRA (Association of Behavioural Researchers on Asians) and cE-Bs (Centre for Environment-Behaviour Studies), Faculty of Architecture, Planning \& Surveying, Universiti Teknologi MARA, Malaysia.

DOI: https://doi.org/10.21834/ebpj.v5i14.2334 
and personal commitments (Ezat et al., 2012). The CPCP of dying persons have also been identified as being at higher risk for health problems and increased mortality rates than the general population (Perkins et al., 2013)

Strengthening psychological and psychosocial resources can promote healthy wellbeing of the CPCP (Fekete et al., 2017). Coping strategies used by cancer CPCP seem to influence their psychosocial adaptation and psychophysiological outcomes (Teixeira et al., 2018). For example, informal CPCP with problem-based coping reported more regular exercise, have adequate sleep, less smoking or binge drinking, than those using emotion-focused coping (Litzelman et al., 2018). Through effective coping strategy, early palliative care approaches in symptoms management, psychosocial care and spiritual support for the CPCP may improve quality of life (Estel et al., 2017). While several studies have been done to investigate coping strategy for patients with palliative cancer treatment (Chirico et al., 2017), studies to describe the coping strategy of CPCP is still very limited. It is crucial to managing stress among CPCP to help reduce their emotional burden and identify their needs to ensure the health and better quality of life.

In Malaysia, there are several local studies have been done investigating depression and coping strategy of cancer patients ( $\mathrm{Ng}$ et al., 2017; Yahaya et al., 2015). Problem-focused coping strategies were commonly used, but emotion-focused strategies were found to be used more increasingly when patients have more severe physical and psychological distress (Yahaya et al., 2015). Religious coping (an example of emotion-focused coping), has been suggested by $\mathrm{Ng}$ et al. (2017) to be used commonly by those cancer patients who had anxiety and depression. Given about one in three of cancer patients suffering from psychological distress on top of their physical misery due to cancer ( $\mathrm{Ng}$ et al., 2017), surely the burden of caregiving those patients is equally high. Hence, identifying the coping strategies of the CPCP is essential so that both patients and the CPCP are maintained healthy.

Currently, the gap is clear that sparse of knowledge on depression and coping style of the CPCP to inform effective ways of managing stress related to the caregiving burden and its implications. Hence, this study aims to: i) determine the prevalence of major depressive disorder (MDD) among the CPCP and, ii) investigate the contributing factors for MDD, including how coping strategy associated with MDD.

\subsection{Methodology}

\subsection{Study design, setting and data collection}

This was a cross-sectional study to determine the prevalence of the major depressive disorder (MDD) among CPCP and its associated factors. It was carried out in Palliative Cancer Clinic of one of the Public Hospitals in the Northern State of Malaysia, which provides palliative care for more than 800 cases of cancer patients every year.

\subsection{Data collection and assessment tools}

Participants were selected using convenience sampling. The CPCP was an individual attending the clinic and accompanying patient in the ward and self-declared her or himself as the person who had assumed the responsibility for caregiving of the palliative cancer patient. The CPCP may or may not related by the family tie, live with the patient, involved with decision-making regarding the patient. Other inclusion criteria include CPCP aged between 18 to 65 years old, able to communicate fluently in Bahasa Malaysia or English and able to give informed consent were included in the study. Those with a lack of mental capacity (mentally disturbed, intellectual disability, etc.) were excluded.

The CPCP were assessed with the Mini International Neuropsychiatric Inventory (MINI) for the diagnosis of MDD (Nordin et al., 2017). The MINI is a locally validated structured diagnostic interview instrument which was used to diagnose MDD following the Diagnostic and Statistical Manual of Mental Disorders Fifth Edition (DSM-5)(Mukhtar et al., 2012). The term "major depressive disorder or MDD" was used when the participant was confirmed to have this disorder using the diagnostic criteria of MDD set by MINI.

The Proforma questionnaire collected data on CPCP' sociodemographic background, caregiving backgrounds and patients' background. Caregiving backgrounds include CPCP' relationship to the patient, their status of living with patient, duration of caregiving, the voluntariness of caregiving, involvement in making the decision, history of training for caregiving and the presence of physical illness. Patients' background includes age, duration of illness, presence and number of physical symptoms, number of admission, Eastern Cooperative Oncology Group (ECOG) Score (scored by treating oncologist), self-care capabilities and hospice support. The CPCP' support was assessed using a locally validated questionnaire; the Multidimensional Scale of Perceived Social Support (MSPSS)(Ng et al., 2010). The CPCP' types of coping were measured with Brief-COPE, a 28 items Likert scale that measures 14 dimensions of coping strategy. It has been translated into Malay and validated with internal consistencies ranging from 0.51 to 0.99 (Yusoff et al., 2009).

\subsection{Statistical Analysis}

Data were analysed using the Statistical Package for the Social Sciences (SPSS) version 23. Data were not normally distributed, hence nonparametric tests were used. Univariate and multivariate analyses were carried out to determine the significance of the association between MDD and various factors. The p-value of less than 0.05 with a confidence interval of $95 \%$ was taken as statistically significant.

\subsection{Ethics}

Ethical approval was obtained from the Medical and Research Ethics Committee of National Clinical Research Center (CRC) Ministry of Health, Medical and Research Ethics ((5) KKM/NIHSEC/P17-910), Committee Faculty of Medicine Universiti Teknologi MARA, Medical and Research Ethics Committee, University Teknologi MARA (REC/171/17) and Medical and Research Ethics Committee Clinical Research Center (CRC) of the respective hospital prior to commencing the study. 


\subsection{Findings}

\subsection{Depression among caregivers}

Of 131 participants, 8 (6.1\%) had MDD, diagnosed using MINI (Major depressive disorder criteria)

\subsection{The Caregivers' Factors}

\section{- Sociodemographic background}

The median (IQR) age group of the CPCP was 42.00 (32.00) years. There were more female $(81 ; 61.83 \%)$ than male $(50 ; 38.17 \%)$ CPCP were enrolled. The participants were predominantly Malays (110; 83.96\%), married (90; 68.71\%) and Muslim (110; $83.96 \%)$. Two third of them had below tertiary level education $(87 ; 66.41 \%)$, half were unemployed $(72 ; 54.96 \%)$ and the majority was at the lowest economic position (income below RM1310) (89; 67.9\%).

\section{- Coping strategy}

Table 1 shows the 14 dimensions of coping strategy based on Brief-COPE. The five most commonly used coping were religious coping, acceptance, active coping, positive reframing and the use of instrumental support.

Table 1: The Rank of Coping Strategy Among the CPCP By Descending Order.

\begin{tabular}{clc}
\hline Rank & \multicolumn{1}{c}{ Coping Strategy } & Median (IQR) \\
\hline 1 & Religious & $8.00(2)$ \\
2 & Acceptance & $7.00(2)$ \\
3 & Active Coping & $6.00(3)$ \\
4 & Positive Reframing & $6.00(3)$ \\
5 & Use of Instrumental Support & $6.00(4)$ \\
6 & Planning & $6.00(2)$ \\
7 & Use of Emotional Support & $5.00(3)$ \\
8 & Self-Distraction & $4.00(3)$ \\
9 & Venting & $4.00(3)$ \\
10 & Humour & $4.00(3)$ \\
11 & Denial & $2.00(2)$ \\
12 & Self-Blame & $2.00(1)$ \\
13 & Behavioural Disengagement & $2.00(0)$ \\
14 & Substance Use & $2.00(0)$ \\
\hline Interpretation: 0-2.00: I haven't been doing this at all; 2.01-4.00: I've been doing this a little bit; 4.01-6.00: I've been doing this a medium
\end{tabular}

\section{- Caregiving factors}

Most of the CPCP lived with the patient $(123 ; 80.2 \%)$; less than half were the children $(53 ; 40.46 \%)$, followed by spouse $(37 ; 28.2 \%)$, parents $(11 ; 8.39 \%)$ and siblings $(3 ; 2.29 \%)$. Others were in-laws, relatives, friends or neighbours $(27 ; 20.61 \%)$. Majority of the participants were physically healthy $(94 ; 71.76 \%)$. The median (IQR) duration of taking care of the patient (since the cancer was first diagnosed) was 0.50 (1.90) years. Most of the CPCP described that they took up caregiving by voluntary basis $(123 ; 93.9 \%)$. More than half stated that patients made their own major decisions on their treatment $(71 ; 54.2 \%)$. Majority of the CPCP did not have any training on handling palliative cancer patients (118; $90.1 \%)$.

\section{- Perceived social support}

Based on MSPSS, overall by descending order, the participants perceived support came highest from the family (Med=5.50; IQR=2), followed by moderate support from significant others (Med=5.00; IQR=1.88) and moderate support from friends (Med=5.00; IQR=1.50). Overall the perceived total support among CPCP was noted to be high (Med=5.17; IQR =1.17).

\subsection{The Patients' Factors}

\section{- Patients' background}

The patients' median (IQR) age was 63.00 (18.00) years. The median (IQR) duration of illness since first diagnosed with cancer was 2.00 (2.50) years. Majority complained of having physical symptoms (112; 85.49\%), with median $2.00(2.50)$ number of physical symptoms. Median (IQR) number of admissions was 1.00 (3.00) times since the time of diagnosis with cancer. Most of the patients had an ECOG score of 3 to 4 , which indicated that the majority of the patients were capable only a limited self-care to none $(80 ; 61.07 \%)$. Majority of the patients and caregivers were not receiving hospice support $(117 ; 89.31 \%)$.

\section{- Type of cancer}

The most common type of cancer is of the digestive organs $(41 ; 31.29 \%)$, followed by breast $(23 ; 17.55 \%)$ and female genital organ $(13$, $9.92 \%)$. Others were malignant neoplasms of lip, oral cavity and pharynx, urinary tract, lymphoid, hematopoietic and related tissue, male 
genital organs, mesothelium and soft tissue, thyroid and other endocrine glands, ill-defined, other secondary and unspecified sites, melanoma and other malignant neoplasms of skin and neoplasms of unspecified behaviour.

\subsection{Contributing factors of MDD among caregivers}

Univariate analysis using Mann-Whitney U Test indicated significant differences in coping strategy between CPCP with and without MDD were behavioural disengagement $(p=0.010)$, positive reframing $(p=0.003)$, religious $(p=0.025)$ and self-blame $(p=0.034)($ Table 2$)$. Other significant differences between CPCP with and without MDD were total perceived social support received by caregivers $(p=0.034)$ and patient's age $(p=0.033)$.

\begin{tabular}{|c|c|c|c|}
\hline \multirow[t]{2}{*}{ Coping Strategy } & \multicolumn{2}{|c|}{$\begin{array}{l}\text { Depressive disorder } \\
\text { Median (IQR) }\end{array}$} & \multirow[t]{2}{*}{ p-value } \\
\hline & Yes $(n=8)$ & No $(n=123)$ & \\
\hline Self-distraction & $4.00(3.00)$ & $4.00(3.00)$ & 0.876 \\
\hline Active coping & $5.00(3.00)$ & $6.00(2.00)$ & 0.058 \\
\hline Denial & $3.00(2.00)$ & $2.00(3.00)$ & 0.837 \\
\hline Substance use & $2.00(0.00)$ & $2.00(0.00)$ & 0.539 \\
\hline Use of emotional support & $5.00(3.00)$ & $5.00(3.00)$ & 0.273 \\
\hline Use of instrumental support & $4.50(4.00)$ & $6.00(3.00)$ & 0.141 \\
\hline Behavioural disengagement & $3.00(5.00)$ & $2.00(0.00)$ & 0.010 * \\
\hline Venting & $5.00(2.00)$ & $4.00(7.00)$ & 0.100 \\
\hline Positive reframing & $3.50(2.00)$ & $6.00(2.00)$ & 0.003 * \\
\hline Planning & $4.50(3.00)$ & $6.00(2.00)$ & 0.147 \\
\hline Humour & $3.00(2.00)$ & $4.00(3.00)$ & 0.286 \\
\hline Acceptance & $4.00(4.00)$ & $7.00(2.00)$ & 0.058 \\
\hline Religious & $6.50(4.00)$ & $8.00(1.00)$ & $0.025^{*}$ \\
\hline Self-blame & $4.50(4.00)$ & $2.00(1.00)$ & $0.034^{*}$ \\
\hline
\end{tabular}

All these significant factors were included in the multiple logistic regression. After controlling the confounding variables, multiple logistic regression indicated that CPCP' coping strategy that significantly associated with MDD among caregivers include behavioural disengagement and positive reframing. The model was significant; Goodness of fit model by Cox \& Snell $\mathrm{R}^{2}$ is $18.0 \%$, and Nagelkerke $\mathrm{R}^{2}$ is $48.8 \%$. The CPCP who adopted coping strategy of behavioural disengagement had 1.84 odds to have MDD $(p=0.04, A O R=1.84$, $95 \% \mathrm{Cl}=1.03-3.28)$. The odds for positive reframing was less than 1 indicating that positive reframing coping strategy was a protective factor for $\operatorname{MDD}(p=0.03, A O R=0.38, C l=0.15-0.93)$.

\subsection{Discussion}

We found about $6 \%$ of caregivers in this study had MDD. This finding is higher than other multi-centre studies which also used diagnostic instrument in their study (Vanderwerker et al., 2005). Using the Structured Clinical Interview for the DSM-IV (SCID), the authors found only $4.5 \%$ of the caregivers had a major depressive disorder. These finding, however, was lower than the percentage of depression in the general population (James et al., 2018). Perhaps, bereavement and caregiving those with cancer receiving palliative care alone may not contribute much to depression compared to other well-known risk factors such as childhood neglect, trauma, and violence and acute life events (such as financial crisis) (Herrman et al., 2019).

To ensure the health of the CPCP and the patient, both should have healthy coping strategies. Our study indicates that the best way for caregivers to cope with the stress and protect themselves from depression is by using positive reframing, supporting the previous findings found by other researchers (Litzelman et al., 2018). Having positive reframing type of coping, encourages the caregivers to analyse the situation and change their thought from 'seeing the glass half empty, to see the glass half full'. Positive reframing may not change the patients' illness condition totally, but it may undoubtedly reduce the negative perceptions and put things into a healthier viewpoint. In a review of psychological adaptation during the cancer experience, the authors indicated that psychosocial interventions (including positive reframing) might enhance the psychological and physiological adaptation indicators (such as neuroendocrine changes) in cancer patients. However, less is known about whether it may influence tumour activity, tumour growth-promoting processes, recurrence and survival rates of the patients (Antoni, 2013). In an interesting study among breast cancer patients, using positive reframing has been shown to reduce the stress experienced by both the patients and their partner (Robbins et al., 2019). Furthermore, in a review study of caregiving, Marino, Haley, and Roth (2017) suggested that act of caregiving is perceived positive when the caregivers feel satisfied and happy, have thoughts of having a purpose, meaning, and direction in life, have autonomous and selfacceptance thoughts while caring for the ill patient. These create constructive personal growth, positive relationship and sense of mastery of the challenges they are facing (Marino et al., 2017).

On the contrary, our study indicated that using behavioural disengagement type of coping may increase the chance of having a depressive disorder. This type of coping involves responses such as avoidance, denial, and wishful thinking; the style of diverting away from dealing with the stressor and/or its related emotions (Dijkstra \& Homan, 2016). The CPCP with this type of coping acting as though the stressor (having cancer or its complication) does not occur, so that it does not have to be reacted to it, behaviourally or emotionally. On the other hand, he or she may have a fantasy (such as cancer may be cured by itself) which is damaging to the cancer patients 
(Carver \& Connor-Smith, 2010). Several studies have shown that using this type of coping may result in more negative consequences of the stressor than other types of active coping strategies (Dijkstra \& Homan, 2016).

The CPCP in our study had used mostly religious coping; similar to those used by the CPCP in other Islamic countries (Riaz \& Rashid, 2019). This condition perhaps occurred because our study had recruited over-representation of Malay Muslims who mostly embrace religion as part of their life and logistically, there is a higher proportion of this group of people in the northern part of Malaysia where the study was carried out. Unlike another local study which recruited samples in the city centre, $\mathrm{Ng}$ et al. (2017) found that depression was inversely related to the practices of private religious activities, we found no relationship between the religious type of coping and depression. Other local researchers who collected data from Sarawak (East Malaysia) have also found no relationship between religious coping and burden of caregiving and depression (Kong \& Guan, 2019). Perhaps, this limitation should be rectified by using stratified sampling strategy so that participants from various religious belief can be equally represented. Nonetheless, other researchers elsewhere have suggested that spiritual and religious coping improves both patients' and caregivers' quality of life, wellbeing, strength in faith, satisfaction and comfort (Khanjari et al., 2018).

\subsection{Conclusion and Recommendations}

The findings of this research are relevant to inform authorities of the need for clinicians to address factors underpin MDD among the CPCP. The type of coping used by the CPCP should be addressed comprehensively to minimise caregiving burden, maintain the psychological and physical health of the CPCP and to prevent complications. Enhancing knowledge of stress prevention through effective coping strategy and early detection of depression among caregivers is crucial so that early and fast treatment and counselling can be offered to them. Together with coping strategies, the support system is equally essential to prevent depression among them. It is recommended that the CPCP who have MDD to be given a chance to get access to effective treatment and rehabilitation. This study provides insights to the contributing factors of MDD and the role of coping strategies while providing caregiving among the CPCP; nevertheless, we would like to inform that the study was limited by its design and suggest a more robust prospective study, and larger sample sizes to determine the causal factors for depression among the CPCP. We are aware that many other personal and environmental factors that could influence depression among them.

\section{Acknowledgements}

We would like to express our appreciation to all patients with cancer and their caregivers who had volunteered to participate in this study and all agencies, and staff who had contributed to the study.

\section{Reference}

Antoni, M. H. (2013). Psychosocial intervention effects on adaptation, disease course and biobehavioral processes in cancer. Brain, behavior, and immunity, 30, S88S98.

Carver, C. S., \& Connor-Smith, J. (2010). Personality and Coping. Annu. Rev. Psychol, 61, 679-704.

Chirico, A., Lucidi, F., Merluzzi, T., Alivernini, F., De Laurentiis, M., Botti, G., \& Giordano, A. (2017). A meta-analytic review of the relationship of cancer coping selfefficacy with distress and quality of life. Oncotarget, 8(22), 36800.

Dijkstra, M., \& Homan, A. C. (2016). Engaging in rather than disengaging from stress: Effective coping and perceived control. Frontiers in psychology, 7, 1415.

Estel, S., Rücker, G., Friederich, H. C., Villalobos, M., Thomas, M., Hartmann, M., \& Haun, M. W. (2017). Early palliative care for adults with advanced cancer. The Cochrane Database of Systematic Reviews, 2017(6)

Ezat, W., Noraziani, K., \& Sabrizan, O. (2012). Improving quality of life among cancer patients in Malaysia. Asian Pacific Journal of Cancer Prevention, 13(3), $1069-1075$.

Fekete, C., Tough, H., Siegrist, J., \& Brinkhof, M. W. (2017). Health impact of objective burden, subjective burden and positive aspects of caregiving: an observational study among caregivers in Switzerland. BMJ open, 7(12), e017369.

Herrman, H., Kieling, C., McGorry, P., Horton, R., Sargent, J., \& Patel, V. (2019). Reducing the global burden of depression: a Lancet-World Psychiatric Association Commission. The Lancet, 393(10189), e42-e43.

Khanjari, S., Damghanifar, M., \& Haqqani, H. (2018). Investigating the relationship between the quality of life and religious coping in mothers of children with recurrence leukemia. Journal of family medicine and primary care, $7(1), 213$.

Kong, S. V., \& Guan, N. C. (2019). Burden in Family Caregivers of Cancer Patients: The Association with Depression, Religiosity and Religious Coping. Asian Pacific Journal of Cancer Care, 4(4), 171-182.

Litzelman, K., Kent, E. E., \& Rowland, J. H. (2018). Interrelationships between health behaviors and coping strategies among informal caregivers of cancer survivors. Health Education \& Behavior, 45(1), 90-100.

Mahadevan, R., Jaafaraafar, N. R. N., Din, S. H. S., Ahmad, S. N. A., Baharuddin, A., \& Razali, R. (2013). The stress of caregiving: A study of family caregivers of breast cancer patients receiving oncologic treatment at a Malaysian general hospital. Sains Malaysiana, 42(7), 1019-1026. 
Marino, V. R., Haley, W. E., \& Roth, D. L. (2017). Beyond hedonia: A theoretical reframing of caregiver wellbeing. Translational Issues in Psychological Science, 3(4), 400.

Ministry of Health. (2018). National Cancer Registry; Malaysian Study on Cancer Survival (MyScan).

Mukhtar, F., Bakar, A. K. A., Junus, M. M., Awaludin, A., Aziz, S. A., Midin, M., .. Kaur, J. (2012). A preliminary study on the specificity and sensitivity values and interrater reliability of mini international neuropsychiatric interview (MINI) in Malaysia. ASEAN Journal of Psychiatry, 13(2).

Ng, G. C., Siddiq, A. A., Aida, S., Zainal, N., \& Koh, O. (2010). Validation of the Malay version of the Multidimensional Scale of Perceived Social Support (MSPSS-M) among a group of medical students in Faculty of Medicine, University Malaya. Asian Journal of Psychiatry, 3(1), 3-6.

Ng, G. C., Mohamed, S., Sulaiman, A. H., \& Zainal, N. Z. (2017). Anxiety and depression in cancer patients: the association with religiosity and religious coping. Journal of religion and health, 56(2), 575-590.

Nordin, R. B., Kaur, A., Soni, T., Por, L. K., \& Miranda, S. (2017). Construct validity and internal consistency reliability of the Malay version of the 21 -item depression anxiety stress scale (Malay-DASS-21) among male outpatient clinic attendees in Johor. Med J Malaysia, 72(5), 265.

Perkins, M., Howard, V. J., Wadley, V. G., Crowe, M., Safford, M. M., Haley, W. E., ... Roth, D. L. (2013). Caregiving strain and all-cause mortality: evidence from the REGARDS study. Journals of Gerontology Series B: Psychological Sciences and Social Sciences, 68(4), 504-512.

Riaz, S., \& Rashid, A. (2019). Religious Coping and Family Caregivers of Cancer, Cardiac and Kidney Patients. J Psychiatr res treat, 1(2), 1.

Robbins, M. L., Wright, R. C., María López, A., \& Weihs, K. (2019). Interpersonal positive reframing in the daily lives of couples coping with breast cancer. Journal of psychosocial oncology, 37(2), 160-177.

Rumpold, T., Schur, S., Amering, M., Kirchheiner, K., Masel, E., Watzke, H., \& Schrank, B. (2016). Informal caregivers of advanced-stage cancer patients: Every second is at risk for psychiatric morbidity. Supportive Care in Cancer, 24(5), 1975-1982.

Teixeira, R. J., Applebaum, A. J., Bhatia, S., \& Brandão, T. (2018). The impact of coping strategies of cancer caregivers on psychophysiological outcomes: an integrative review. Psychology research and behavior management, 11, 207.

Vanderwerker, L. C., Laff, R. E., Kadan-Lottick, N. S., McColl, S., \& Prigerson, H. G. (2005). Psychiatric disorders and mental health service use among caregivers of advanced cancer patients. Journal of clinical oncology: official journal of the American Society of Clinical Oncology, 23(28), 6899.

Wen, F.-H., Chen, J.-S., Chou, W.-C., Chang, W.-C., Shen, W. C., Hsieh, C.-H., \& Tang, S. T. (2019). Family Caregivers' Subjective Caregiving Burden, Quality of Life, and Depressive Symptoms Are Associated with Terminally III Cancer Patients' Distinct Patterns of Conjoint Symptom Distress and Functional Impairment in Their Last Six Months of Life. Journal of pain and symptom management, $57(1), 64-72$

World Health Organization. (2018). Cancer Retrieved 25 February 2020 from https://www.who.int/health-topics/cancer\#tab=tab_1.

Yahaya, N. A., Subramanian, P., Bustam, A. Z., \& Taib, N. A. (2015). Symptom experiences and coping strategies among multi-ethnic solid tumor patients undergoing chemotherapy in Malaysia. Asian Pac J Cancer Prev, 16(2), 723-730.

Yusoff, N., Low, W., \& Yip, C. (2009). Reliability and validity of the Malay version of Brief COPE scale: A study on Malaysian women treated with adjuvant chemotherapy for breast cancer. Malaysian Journal of Psychiatry, 18(1). 